\title{
High-resolution melting analysis for rapid and sensitive MYD88 screening in chronic lymphocytic leukemia
}

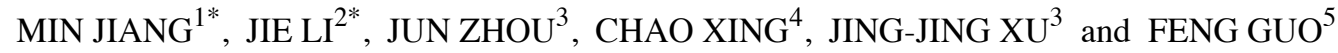 \\ ${ }^{1}$ Department of Blood Transfusion; ${ }^{2}$ Department of Special Requirements Ward; ${ }^{3}$ Center for Clinical Laboratory, \\ The First Affiliated Hospital of Soochow University, Suzhou, Jiangsu 215006; ${ }^{4}$ Department of Laboratory Medicine, \\ The Second Affiliated Hospital and Yuying Children's Hospital of Wenzhou Medical University, Wenzhou, Zhejiang 325000; \\ ${ }^{5}$ Department of Oncology, Nanjing Medical University Affiliated Suzhou Hospital, Suzhou, Jiangsu 215001, P.R. China
}

Received March 3, 2018; Accepted March 29, 2019

DOI: $10.3892 / \mathrm{ol} .2019 .10342$

\begin{abstract}
High resolution melting (HRM) assay is a novel technology for the fast, high-throughput, sensitive, post-PCR analysis of genetic mutations. Myeloid differentiation primary response 88 (MYD88) mutations are frequently reported in chronic lymphocytic leukemia (CLL) and confer a worse prognosis. The objective of the present study was to assess the value of HRM analysis for the rapid screening of MYD 88 mutations in patients with CLL. Genomic DNA samples were extracted from the bone marrow of 129 newly diagnosed patients with CLL. A plasmid with an MYD88-L265P mutation was constructed, and the p.L265P substitution, which is the predominant MYD88 mutation in CLL, was detected using HRM analysis and direct sequencing. The plasmid pCMV-MYD88-L265P-Mu was successfully constructed as a positive control, and was verified by direct sequencing. The normalized and shifted melting curves of 6/129 (4.65\%) samples were clearly different from those of other patients by HRM analysis. In addition, the 794T>C mutation in MYD88 was identified in $6(4.65 \%)$ patients by direct sequencing. Sensitivity evaluation revealed that the HRM assay had a higher sensitivity (to $1 \%$ dilution) than direct sequencing, in addition to being convenient and time-saving. The MYD88 p.L256P mutation has been implicated to be associated with adverse prognosis in CLL. HRM analysis has the potential to
\end{abstract}

Correspondence to: Dr Feng Guo, Department of Oncology, Nanjing Medical University Affiliated Suzhou Hospital, 16 Baita West Road, Suzhou, Jiangsu 215001, P.R. China

E-mail: guofeng27@suda.edu.cn

Dr Jing-Jing $\mathrm{Xu}$, Center for Clinical Laboratory, The First Affiliated Hospital of Soochow University, 188 Shizi Road, Suzhou, Jiangsu 215006, P.R. China

E-mail: xujingjing8623@163.com

*Contributed equally

Key words: high resolution melting, $M Y D 88$, chronic lymphocytic leukemia, direct sequencing be a routine prescreening technique to identify the $M Y D 88$ p.L256P mutation and may facilitate the clinical treatment of CLL.

\section{Introduction}

Chronic lymphocytic leukemia (CLL) is generally known as a heterogeneous disease with different clinical features and disease prognosis. A number of biological features, including immunoglobulin heavy variable (IGHV) mutational status, zeta-chain-associated protein kinase 70, CD38 expression and cytogenetic abnormalities, including myeloid differentiation primary response 88 (MYD88) mutations in leukemic lymphocytes have been reported to be correlated with clinical outcome (1-4). MYD88 protein is encoded by the MYD88 gene, which is located on chromosome 3 p22.2. The MYD88 mutation has been found in various lymphoproliferative disorders, including Waldenström macroglobulinemia, diffuse large B-cell lymphoma and CLL (5-7). In a number of studies, researchers have observed that patients with $M Y D 88$ mutations exhibit high expression levels of genes in the NF- $\mathrm{B}$ signaling pathway, in addition to an early appearance of $\operatorname{CLL}(3,8,9)$. MYD 88 gene mutations have been shown to be correlated with the drug resistance and prognosis of CLL (3). In recent studies, MYD88 mutation rates of $2-5 \%$ in patients with CLL have been reported $(10,11)$. The p.L265P mutation in the MYD88 gene is the main somatic mutation in CLL accounting for $84 \%$ worldwide (12). The p.L265P substitution at exon 5 in MYD88 has been indicated to activate the $\mathrm{NF}-\kappa \mathrm{B}$ pathway, thereby conferring a proliferative and survival advantage to the mutant cells (11-14). However, other studies have reported that p.L265P in MYD88 serves as a favourable prognostic marker in patients with CLL $(8,10)$. The aim of the present study was to find an effective and convenient method for detecting the MYD88 p.L265P mutation.

High resolution melting (HRM) analysis is a technique first established in 2003, that has been developed for the high-throughput and convenient genotyping of individual polymorphic loci (15). The key to this technology is the use of saturating fluorescence dyes, which intercalate into double-stranded DNA during amplification of the DNA without inhibiting the PCR reaction. The dye fluoresces 
strongly when intercalated into the double-stranded DNA, but as the temperature increases during the HRM analysis, the DNA melts and the dye is release without fluorescence. The changes in fluorescence are sequence specific and can be recorded and analyzed by the designed program $(16,17)$.

The aim of the present study was to develop a RT-qPCR analysis method utilizing high-resolution melting technology for the accurate and convenient detection of the MYD88 p.L265P mutation in patients with CLL. The mutations were simultaneously confirmed by direct sequencing analysis, and the sensitivities of the two methods were compared.

\section{Materials and methods}

Clinical specimens. A total of 129 patients, 78 male and 51 female patients, diagnosed with CLL between October 2015 and October 2017 at the First Affiliated Hospital of Soochow University (Suzhou, China) were included in the present study. The mean age of the population was 62.19 years. Patients were newly diagnosed without any prior therapy. Bone marrow samples were collected from the patients (ethics approval no. 709.2). Written informed consent was obtained from all patients. The study was approved by the Ethics Committee of the First Affiliated Hospital of Soochow University.

Genomic ( $g$ )DNA extraction. Lymphocyte cell separation and density gradient centrifugation were used to collect monocytes from the bone marrow samples of the patients with CLL using Histopaque-1077 (Sigma-Aldrich; Merck KGaA; cat no. 10771). Centrifugation speed was $400 \mathrm{x}$ g for $20 \mathrm{~min}$ at room temperature. gDNA was extracted from these cells using a gDNA isolation kit (Omega BIO-TEK; cat no. M6399-00), according to the manufacturer's protocols. Each DNA sample was quantified using a NanoDrop ND-1000 fluorospectrometer (Thermo Fisher Scientific, Inc.), and samples with a A260/280 value between 1.8 and 2.0 were retained.

Examination of the IGHV mutations status. The IGHV mutation status was detected using an IGHV somatic hypermutation assay v2.0 kit (Invivoscribe), according to the manufacturer's protocols. The PCR products were sequenced and considered as unmutated if the homology with the closest germline sequence showed $>98 \%$.

Construction of a plasmid containing wild-type MYD88 gene. The TA cloning kit (Invitrogen; Thermo Fisher Scientific; cat no. C45-0046) was used to prepare a PCR product containing exon 5 of wild-type $M Y D 88$ gene in a plasmid vector. Primer sequences were as follows: Forward, 5'-GTGAATGTGTGC CAGGGGTA-3' and reverse, 5'-GGTTGGTGTAGTCGC AGACA-3'. PCR was performed in a $50 \mu \mathrm{l}$ reaction volume, according to the kit protocol. PCR thermocycling conditions were as follows: $95^{\circ} \mathrm{C}$ for $30 \mathrm{sec}$; 40 cycles of $95^{\circ} \mathrm{C}$ for $30 \mathrm{sec}$, $55^{\circ} \mathrm{C}$ for $60 \mathrm{sec}$ and $72^{\circ} \mathrm{C}$ for $45 \mathrm{sec}$; and then stopped at $10^{\circ} \mathrm{C}$. Gel purification of the PCR fragment was then performed (gel extraction kit; Omega BIO-TEK; cat no. D2500-01). The clone was ligated into vector pCR 2.1 from the TA cloning kit, according to the manufacturer's protocol, and the construct was then transformed into competent $E$. coli cells. The final plasmid pCMV-MYD88-TA, comprising the wild-type exon 5 of $M Y D 88$, was verified by sequencing and stored at $-20^{\circ} \mathrm{C}$.

Site-directed mutagenesis. Site-directed mutagenesis was performed using a Muta-direct ${ }^{\mathrm{TM}}$ Site Directed Mutation kit (cat. no., SDM-125; Beijing SBS Genetech Co., Ltd.) according to the manufacturer's protocol, in order to obtain a plasmid with a p.L265P mutant of MYD88. The following primers were designed as instructed by the kit, and synthesized by Invitrogen (Thermo Fisher Scientific, Inc.): Forward, 5'-CCATCAGAAGCGACCGATCCCCATCAAGTA-3' and reverse, 5'-TACTTGATGGGGATCGGTCGCTTCTGA TGG-3'. PCR was conducted according to the kit protocol. The PCR thermocycling conditions were as follows: $95^{\circ} \mathrm{C}$ for $30 \mathrm{sec}$; 40 cycles of $95^{\circ} \mathrm{C}$ for $30 \mathrm{sec}, 55^{\circ} \mathrm{C}$ for $60 \mathrm{sec}$ and $72^{\circ} \mathrm{C}$ for $45 \mathrm{sec}$; and stopped at $10^{\circ} \mathrm{C}$. The PCR product was treated with $1 \mu \mathrm{l}$ Mutazyme ${ }^{\mathrm{TM}}$ from the kit at $37^{\circ} \mathrm{C}$ for $1 \mathrm{~h}$. Competent $E$. coli DH5 $\alpha$ cells were then transformed with the treated PCR product. Consequently, the final plasmid pCMV-MYD88-L265P-Mu containing the mutated MYD88 was verified by sequencing and stored at $-20^{\circ} \mathrm{C}$.

HRM analysis. HRM PCR primers were designed according to the genomic reference sequences of MYD88 (NG_016964.1). Forward, 5'-GACTGGGCTTGTCCCACC-3' and reverse, 5'-CGCAGACAGTGATGAACCTC-3'. The p.L265P mutation is a $\mathrm{T}$ to $\mathrm{C}$ nucleotide change (c.794T $>C$ ) in exon 5 of the MYD88 gene and results in an amino acid change from leucine (CTG) to proline (CCG) (7).

Fast Evagreen ${ }^{\circledR}$ qPCR Master mix (Biotium) was used with a LightCycler 480 instrument (Roche Diagnostics) for the HRM assay. The final reaction mixture contained: $5 \mu 12 \mathrm{X}$ Fast Evagreen ${ }^{\circledR}$ qPCR Master mix, $1 \mu \mathrm{l} 40 \mathrm{nM}$ forward primer and $40 \mathrm{nM}$ reverse primer, $75 \mathrm{ng}$ gDNA, and PCR water to a total of $20 \mu \mathrm{l}$. The cycling and melting conditions were as follows: $94^{\circ} \mathrm{C}$ for $5 \mathrm{~min} ; 50$ cycles at $94^{\circ} \mathrm{C}$ for $30 \mathrm{sec}, 60^{\circ} \mathrm{C}$ for $30 \mathrm{sec}$ and $72^{\circ} \mathrm{C}$ for $45 \mathrm{sec}$. HRM conditions were as follows: $95^{\circ} \mathrm{C}$ for $1 \mathrm{~min}, 40^{\circ} \mathrm{C}$ for $1 \mathrm{~min}, 65^{\circ} \mathrm{C}$ for $1 \mathrm{sec}$, with a continuous increase in temperature from 65 to $95^{\circ} \mathrm{C}$ at a rate of $0.02^{\circ} \mathrm{C} / \mathrm{sec}$ with 25 signal acquisitions per degree; and cooling at $40^{\circ} \mathrm{C}$ for $30 \mathrm{sec}$. The melting curve analysis was subsequently performed using LightCycler 480 Gene Scanning 1.5 software (Roche Diagnostics). Each sample analysis was repeated twice.

Direct sequencing. Genomic sequence screening of MYD88 (NG_016964.1) in CLL was accomplished through direct sequencing. Forward and reverse primers used in direct sequencing were the same of those in the aforementioned HRM reaction. The PCR mixture contained $2 \mu 1$ 10X PCR buffer, $0.5 \mu 110 \mathrm{nM}$ dNTPs, $0.5 \mu 120 \mathrm{pmol} / \mu 1$ forward primer and reverse primer, $0.1 \mu \mathrm{l}$ TaqDNA polymerase (Invitrogen; Thermo Fisher Scientific, Inc.), $1.2 \mu 11.5 \mathrm{mM}$ $\mathrm{Mg}^{2+}, 1 \mathrm{ng}$ genomic DNA, and PCR water to a total of $20 \mu \mathrm{l}$. The cycling and melting conditions were as follows: $94^{\circ} \mathrm{C}$ for $5 \mathrm{~min}$; and 40 cycles of $94^{\circ} \mathrm{C}$ for $30 \mathrm{sec}, 60^{\circ} \mathrm{C}$ for $30 \mathrm{sec}$ and $72^{\circ} \mathrm{C}$ for $45 \mathrm{sec}$. Final PCR products were qualified and bi-directionally sequenced using an ABI 3730 DNA Analyzer (Applied Biosystems; Thermo Fisher Scientific, Inc.). All the nucleotide changes detected by bi-directional sequencing were 
A

WT

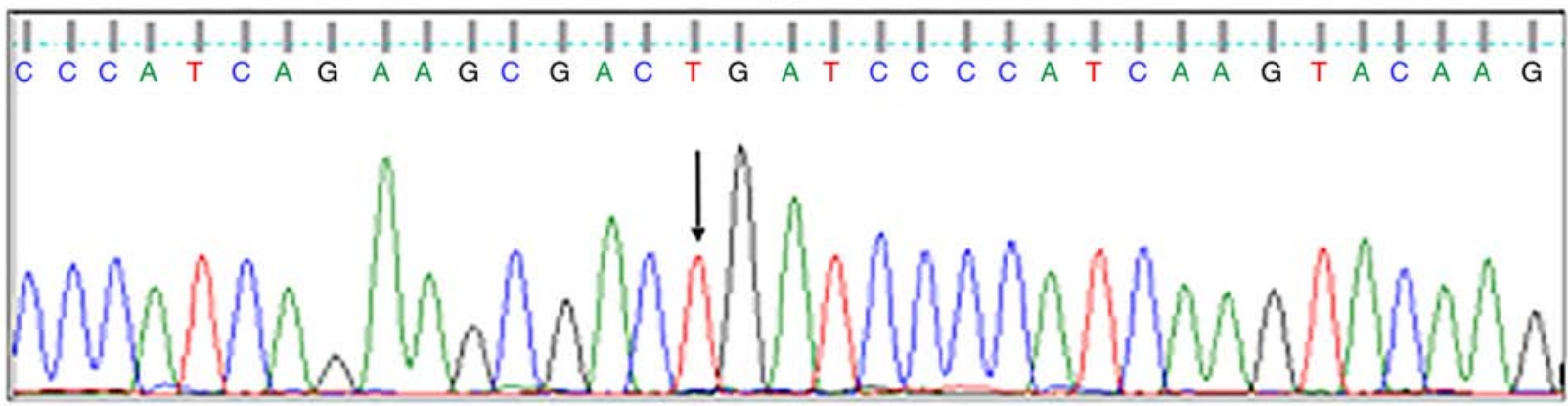

B

pCMV-MYD88-L265P-Mu

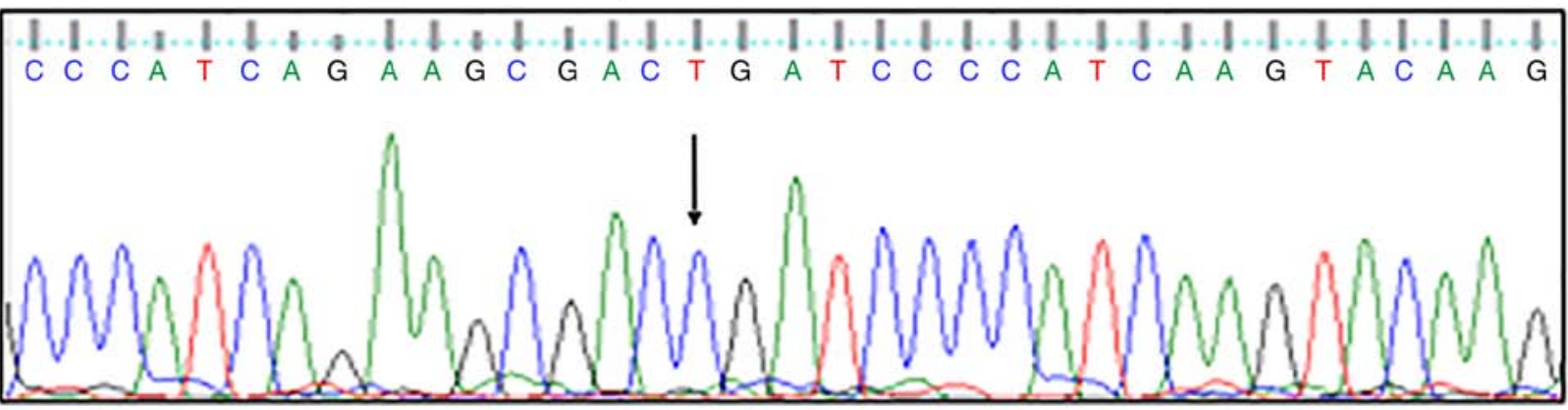

Figure 1. Sequencing result of two plasmids. (A) Sequence of the WT MYD88 plasmid. There is no mutation at position 794 (arrow). (B) Sequence of the mutant MYD88 plasmid pCMV-MYD88-L265P-Mu. There is a mutation at position $794 \mathrm{~T}>\mathrm{C}$ (arrow). MYD88, myeloid differentiation primary response 88; WT, wild-type; Mu, mutated.

inspected using the Sanger COSMIC database (web address: http://cancer.sanger.ac.uk).

Sensitivity determination. The pCMV-MYD88-L265P-Mu plasmid (positive control) was serially diluted with the TA clone plasmid (negative control) in order to evaluate the sensitivity of the HRM assay and direct sequencing assay. Dilutions comprising 100, 50, 20, 10, 5, 1 and $0 \%$ TA clone plasmid were prepared.

\section{Results}

Establishment of site-directed gene mutagenesis. Since no validated cell line containing MYD88 p.L265P exists, the plasmid pCMV-MYD88-L265P-Mu was constructed as a positive control using a Muta-direct Site Directed Mutation kit, according to the manufacturer's protocol. The plasmid pCMV-MYD88-L265P-Mu that was constructed was further verified by direct sequencing. A mutation at position 794 (794T>C) was indicated (Fig. 1).

MYD88 p.L265P mutation detection by HRM assay. For HRM analysis, the optimal temperature and suitable primer concentration were selected to obtain PCR products with efficient amplification and a satisfactory melting profile. LightCycler 480 Gene Scanning 1.5 software was used to analyze the normalized and difference melting curves for the mutation status evaluation of patients. The results revealed that $4.65 \%$ (6/129) of the patients had melting curves and plots that differed from the others. HRM analysis of MYD88 exon 5 revealed a point mutation at position 794 that could be identified by an elevated melting curve that differed from that of the negative control (Fig. 2A and B). Basic characteristics of the patients with CLL, according to MYD88 p.L265P mutations, are presented in Table I. In the analysis of basic characteristics of patients with CLL, IGHV mutations were found in all patients with MYD88 p.L265P mutations. Patients with CLL with MYD88 p.L265P mutations were younger at diagnosis (mean age is lower compared with the wild-type ones).

Screening for MYD88 p.L265P mutations by direct sequencing. All 129 samples analyzed by the HRM assay were further analyzed by direct sequencing. A total of $6(4.65 \%)$ patients were found have a mutation at position $794(794 \mathrm{~T}>\mathrm{C})$ for the MYD88 gene. The results of the HRM assay and direct sequencing were consistent (Fig. 2C).

Sensitivity evaluation by HRM assay and direct sequencing. The obtained pCMV-MYD88-L265P-Mu plasmid was used as a positive control for evaluation of the sensitivity and accuracy of the HRM assay and direct sequencing. The TA clone plasmid was used as a negative control. The negative control was used at serial dilutions of 100, 50, 20, 10, 5, 1 and $0 \%$ to evaluate the relative sensitivities of the two methods. Fig. 3 shows normalized and shifted melting curves, and normalized and temperature-shifted difference plots of the HRM data. The melting curve obtained using $1 \%$ mutated template clearly differed from the negative template. However, the mutation was detectable by direct sequencing when the mutant frequency was $>10 \%$ (Fig. 4). These results indicate that the HRM analytical method for detection of the MYD88 p.L265P mutation has higher sensitivity than direct sequencing. 

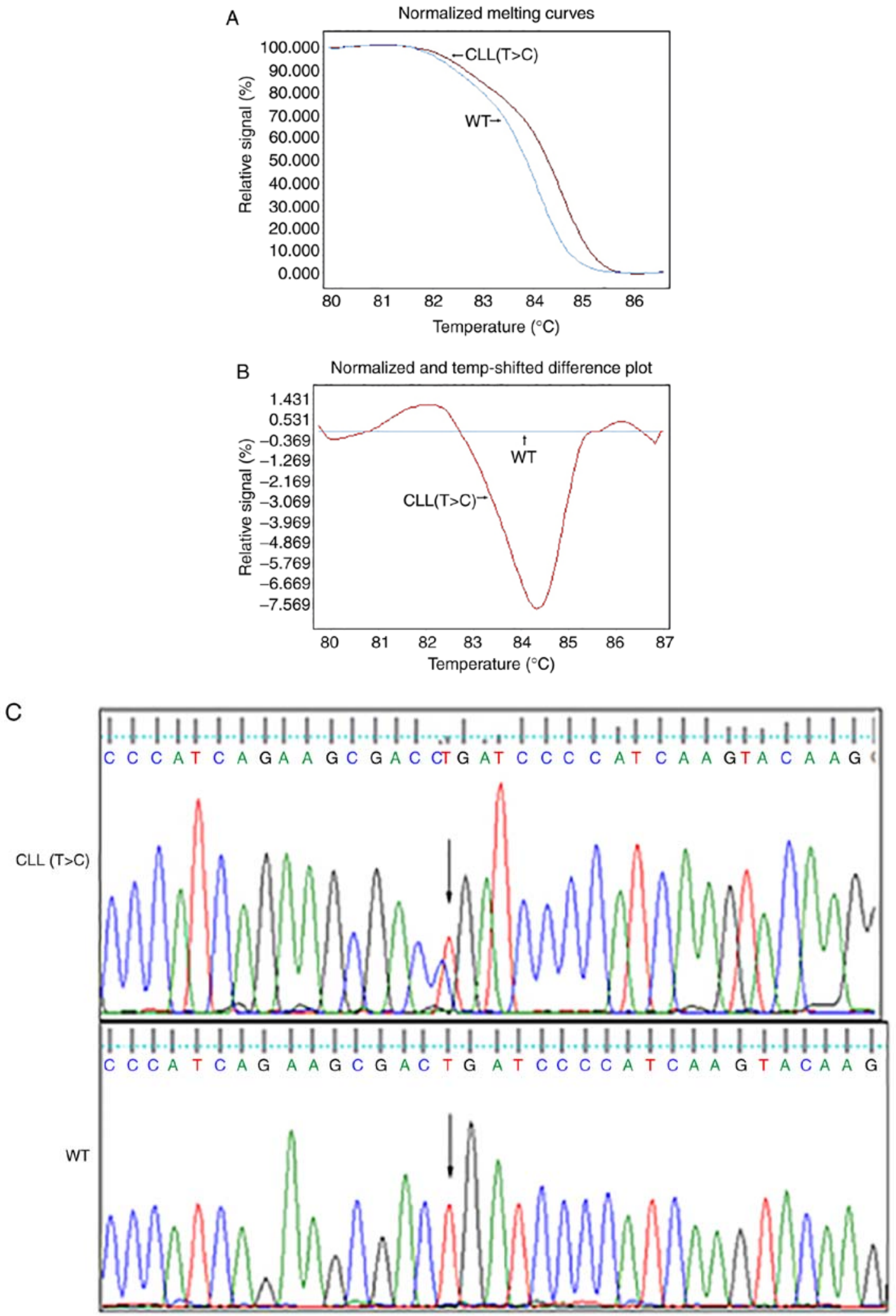

Figure 2. Melting curves, difference plots and sequence traces for the MYD88 p.L265P mutation. (A) Normalized and shifted melting curves of MYD88 p.L265P indicate that the HRM assay was able to distinguish the T>C mutation at position 794 from WT. (B) Normalized and temperature-shifted difference plots indicate that the HRM assay distinguished the T $>C$ mutation at position 794 from WT. (C) Sequencing chromatograms confirmed the T>C mutation at position 794 (arrow). MYD88, myeloid differentiation primary response 88; HRM, high resolution melting assay; WT, wild-type; CLL, chronic lymphocytic leukemia.

\section{Discussion}

The development of personalized and targeted therapies has created an increased demand for the molecular profiling of cancers in order to provide more appropriate treatment (18). CLL is the second most common type of leukemia in adults in the western world. It is characterized by the proliferation and progressive accumulation of mature clonal B lymphocytes 
Table I. Characteristics of patients with CLL according to MYD88 p.L265P mutation status.

\begin{tabular}{lccc}
\hline Characteristics & Value & MYD88 wild type (n=123) & MYD88 p.L256P (n=6) \\
\hline Mean age, years & 62.19 & 62.34 & 56.00 \\
Sex (male/female) & $78 / 51$ & $72 / 51$ & $6 / 0$ \\
IGHV mutated, (n/N) & $12 / 129$ & $0 / 123$ & $6 / 6$
\end{tabular}

CLL, chronic lymphocytic leukemia; MYD88, myeloid differentiation primary response 88; IGHV, immunoglobulin heavy variable. n, the number of patients with MYD88 wild-type and MYD88 p.L256P; N, the total number of patients with CLL.
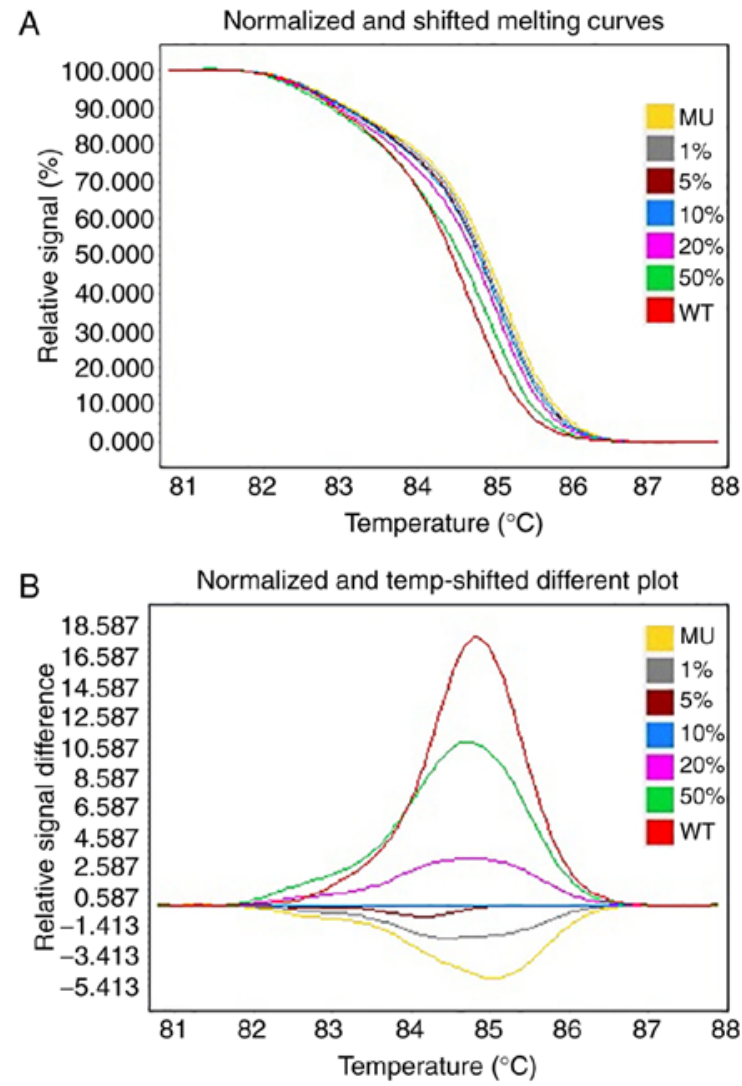

Figure 3. Validation and sensitivity testing for the HRM assay. The TA clone plasmid (WT) was used as a negative control. Various dilutions of WT were used to generate (A) normalized and shifted melting curves and (B) normalized and temperature-shifted difference plots of the HRM data. The melting curve for $1 \%$ WT template clearly differed from the positive template. HRM, high resolution melting assay; WT, wild-type; MU, mutated.

in the bone marrow, lymphoid tissues and blood $(19,20)$. In previous studies, numerous molecular indices have been shown to be informative in predicting the disease course and treatment direction, including TP53, BIRC3, SF3B1, NOTCHI and $M Y D 88$ (21-23). These genes, with the exception of MYD88, have been associated with a shorter time to treatment, as well as overall survival (24). MYD88 is a cytoplasmic soluble protein of the interleukin-1 receptor/Toll-like receptor (TLR) pathway (25). TLRs in B cells may act as a trigger for a non-specific immune response following the recognition of certain molecular patterns, and CLL cells express a pattern of TLRs similar to that of normal memory B cells (26). The stimulation of TLRs activates the NF- $\mathrm{B}$ and mitogen-activated protein kinase signaling pathways and protects CLL cells from spontaneous apoptosis (8). Therefore, TLR activation may be relevant to the pathogenesis of CLL. It has been reported that the predominant mutation of CLL, which is a p.L265P substitution within exon 5 in $M Y D 88$, may lead to NF- $\kappa \mathrm{B}$ stimulation and thereby provide a proliferation and survival advantage for CLL mutant cells. MYD88 mutations have been reported in $2-5 \%$ of CLL cases, with the majority of cases carrying the p.L265P substitution $(20,21)$.

An HRM assay was conducted in the present study as a potentially reliable, rapid and low-cost genotyping assay for the detection of the MYD88 p.L256P mutation in CLL. To the best of our knowledge, this is the first study reporting MYD88 p.L256P mutation screening in the bone marrow samples of Chinese patients with CLL. A relatively low frequency of the MYD88 hotspot mutation $(4.65 \%)$ was identified. Due to the low number of CLL cases with MYD88 mutations, it was not possible to detect an association with clinical outcome.

The HRM analysis of amplicons is based on fluorescence measurements during the melting of double-strand DNA in the presence of saturating DNA-binding dyes, which are used to create a melting curve, derivative plot or difference plot for analysis (27). The present study used the HRM assay to generate specific melting profiles, which distinguished between wild-type and mutated variants due to differences in nucleosides. The normalized and shifted melting curves of 6/129 samples were clearly different from those of samples from the other patients.

In order to confirm the reliability of the HRM analysis, all the mutated samples were simultaneously analyzed by direct sequencing. Direct sequencing identified 6 samples that harbored the MYD88 p.L256P mutation, and was consistent with the results of the HRM assay. The mutation frequency was similar to that found in previous studies using other assay methods (28-30). The HRM analysis in the present study was highly sensitive, and was able to detect a mutation rate of $1 \%$. This indicates that the sensitivity of the HRM analysis was higher compared with that of direct sequencing analysis, with a sensitivity of $10 \%(30,31)$.

The protein truncation test (PTT), DNA sequencing, PCR-single-strand conformation polymorphism (PCR-SSCP), conformation sensitive gel electrophoresis (CSGE), and HRM methods are often used to detect gene mutations. PTT uses radioactive labels for protein detection (32). PCR-SSCP is simple to perform, but is time-consuming and has low sensitivity for the detection of genetic variations (33). CSGE has high efficiency and relatively high sensitivity, but is also time-consuming and expensive (34). Direct sequencing is 

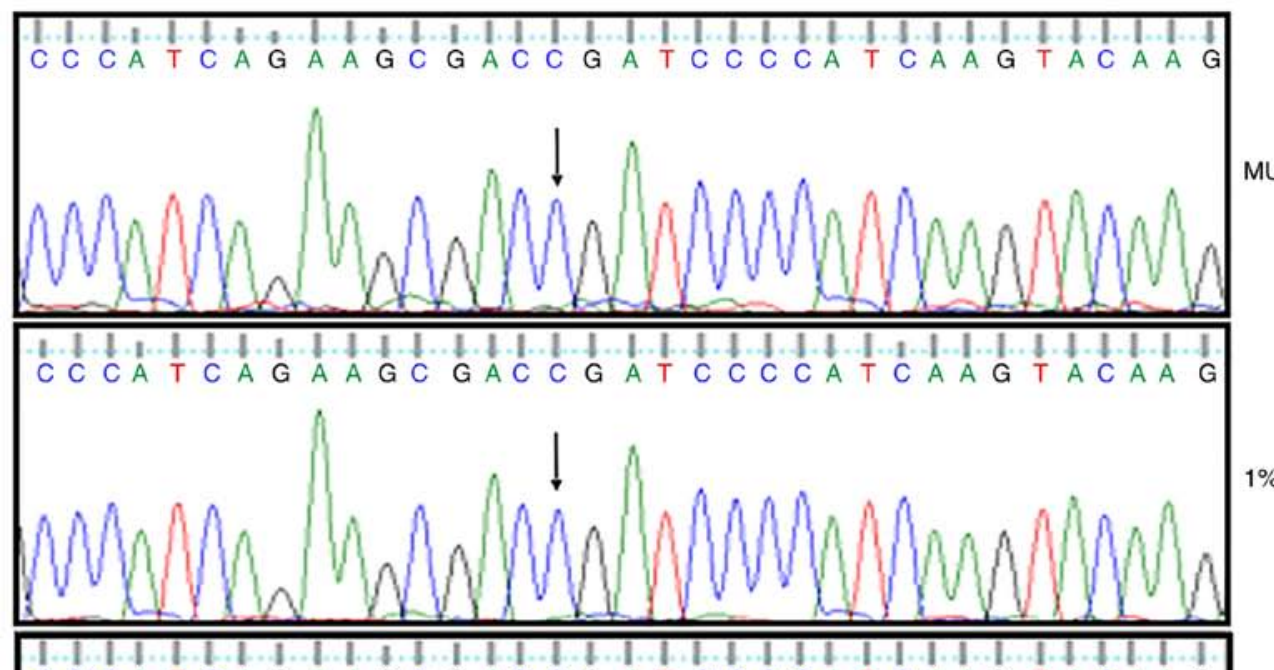
C C C A T C A G A A G C G AC C G A T C C C C A T C A A G T A C A A G

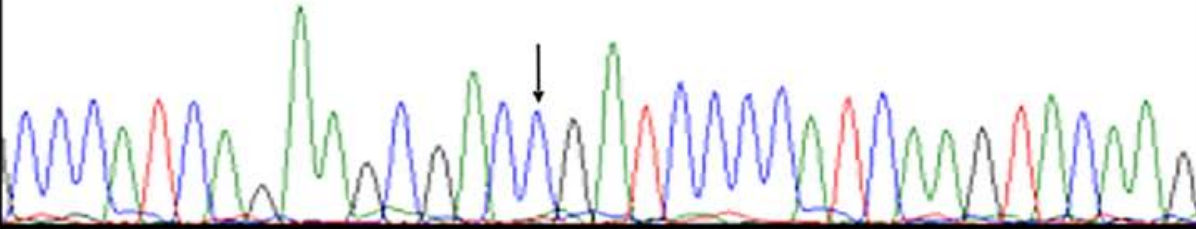

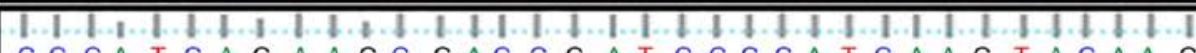
C C C A T C A G A A G C G A C G A T C C C C A T C A A G T A C A A G

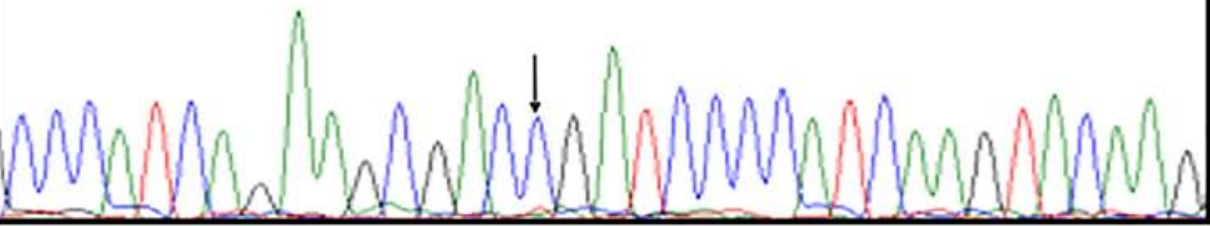

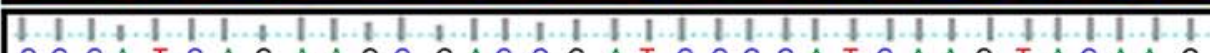
$C \subset C A T C A G A A G C G A C \subset G A T C C C C A T C A A G T A C A A G$

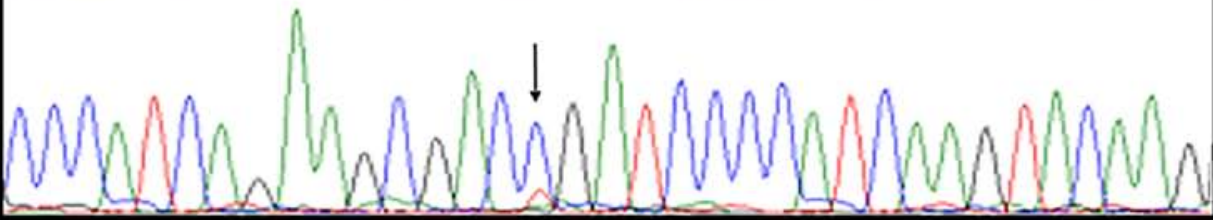
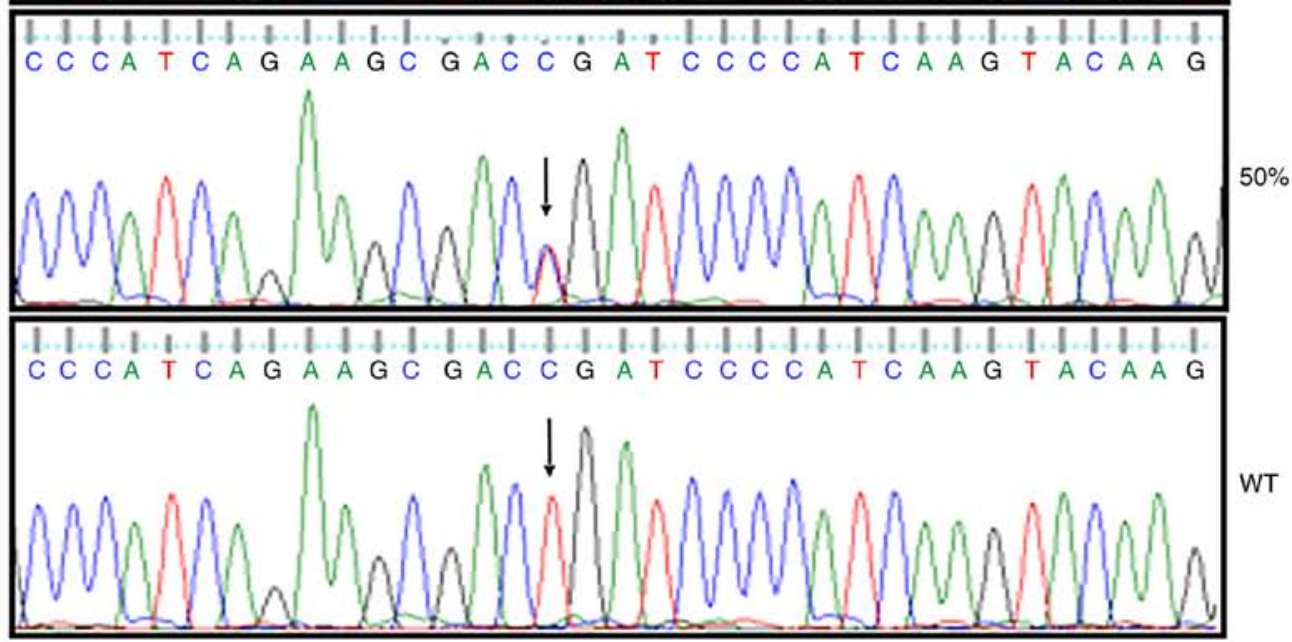

Figure 4. Validation and sensitivity testing for direct sequencing. Direct sequencing results of $M Y D 88$ p.L265P mutations at serial dilutions (100, 50, 20, 10, 5, 1 and $0 \%$ ) with negative control. The sensitivity for direct sequencing was indicated to be $10 \%$. Arrows indicate the mutation site. MYD 88 , myeloid differentiation primary response 88 ; WT, wild-type; MU, mutated.

considered the gold standard, and can identify any mutation in a DNA sequence (35). However, its high cost, limited sensitivity and extensive testing time limit its application. Therefore, HRM analysis provides an alternative technique 
for the detection of mutations. The PCR amplification and subsequent analysis conducted during the HRM assay are performed in a single closed tube, and so this method is more convenient and faster than other scanning methods $(12,29)$. The use of a closed-tube in the HRM analysis minimizes the risk of contamination of the post-PCR product during scanning, while also decreasing the processing time. Notably, in the present study, the quantity of gDNA required was only $75 \mathrm{ng}$, and the whole testing procedure took only $2 \mathrm{~h}$.

The present study suggests the value of HRM analysis as a screening tool for mutations. However, it also has certain limitations (36). Firstly, the presence of undiscovered polymorphisms in the genes may interfere with genotyping. Therefore, this study deliberately designed amplicon lengths of only $149 \mathrm{bp}$, because the wild-type and heterozygote curves become too small to distinguish as the amplicon length increased. Secondly, the HRM assay cannot detect mutations containing an entire exon or deletions of entire genes and exons. Thirdly, the HRM method requires that the DNA to be analyzed is of good quality. Therefore, the present study used bone marrow samples to obtain gDNA with good quality. In addition, the sample size in the present study was small, and larger studies are required to further validate the results.

In conclusion, HRM analysis was demonstrated to be a feasible method for the clinical detection of the MYD88 p.L256P mutation. It is more sensitive than DNA sequencing, cost-efficient and has a reduced processing time. To the best of our knowledge, this is the first time that the HRM assays have been used in the detection of MYD88 mutation in patients with CLL. This study indicates that HRM analysis may be useful in a clinical setting for the screening of MYD88 mutations during the preliminary diagnosis or clinical course of CLL.

\section{Acknowledgements}

We would like to acknowledge Professor Dandan Liu and Dr Lan Dai for their excellent technical assistance and suggestions.

\section{Funding}

This study was supported by grants from the National Natural Science Foundation of China (grant nos. 81400154, 81500068 and 61772357), the Natural Science Foundation of Jiangsu Provincial (grant no. BK20151211) and the Project of Invigorating Health Care through Science, Technology and Education, Jiangsu Provincial Medical Youth Talent (grant no., QNRC2016725).

\section{Availability of data and materials}

The datasets supporting the conclusions of this article are included in the article.

\section{Authors' contributions}

FG and JX designed the research. MJ and JL performed the research and analysed the data. JZ and CX collect the samples and performed the research. MJ wrote the paper. All authors have read and approved the final version of this manuscript.

\section{Ethics approval and consent to participate}

The study was approved by the Ethics Committee of the First Affiliated Hospital of Soochow University. Written informed consent was obtained from all patients.

\section{Patient consent for publication}

The patients included in this study had provided written informed consent for the publication of this article.

\section{Competing interests}

The authors declare that there is no conflict of interests that could be perceived as prejudicing the impartiality of the research reported.

\section{References}

1. Hamblin TJ, Davis Z, Gardiner A, Oscier DG and Stevenson FK: Unmutated $\operatorname{IgV}(\mathrm{H})$ genes are associated with a more aggressive form of chronic lymphocytic leukemia. Blood 94: 1848-1854, 1999.

2. Baliakas P, Hadzidimitriou A, Sutton LA, Rossi D, Minga E, Villamor N, Larrayoz M, Kminkova J, Agathangelidis A, Davis Z, et al: Recurrent mutations refine prognosis in chronic lymphocytic leukemia. Leukemia 29: 329-336, 2015.

3. Puente XS, Pinyol M, Quesada V, Conde L, Ordóñez GR, Villamor N, Escaramis G, Jares P, Beà S, González-Díaz M, et al: Whole-genome sequencing identifies recurrent mutations in chronic lymphocytic leukemia. Nature 475: 101-105, 2011.

4. Wang L, Lawrence MS, Wan Y, Stojanov P, Sougnez C, Stevenson K, Werner L, Sivachenko A, DeLuca DS, Zhang L, et al: SF3B1 and other novel cancer genes in chronic lymphocytic leukemia. N Engl J Med 365: 2497-2506, 2011.

5. Treon SP, Xu L, Yang G, Zhou Y, Liu X, Cao Y, Sheehy P, Manning RJ, Patterson CJ, Tripsas C, et al: MYD88 L265P somatic mutation in Waldenström's macroglobulinemia. N Engl J Med 367: 826-833, 2012.

6. Wang CZ, Lin J, Qian J, Shao R, Xue D, Qian W, Xiao GF, Deng ZQ, Yang J, Li Y and Chen XX: Development of high-resolution melting analysis for the detection of the MYD88 L265P mutation. Clin Biochem 46: 385-387, 2013.

7. Xu L, Hunter ZR, Yang G, Zhou Y, Cao Y, Liu X, Morra E, Trojani A, Greco A, Arcaini L, et al: MYD88 L265P in Waldenström's macroglobulinemia, immunoglobulin M monoclonal gammopathy, and other B-cell lymphoproliferative disorders using conventional and quantitative allele-specific polymerase chain reaction. Blood 121: 2051-2058, 2013.

8. Martínez-Trillos A, Pinyol M, Navarro A, Aymerich M, Jares P, Juan M, Rozman M, Colomer D, Delgado J, Giné E, et al: Mutations in TLR/MYD88 pathway identify a subset of young chronic lymphocytic leukemia patients with favorable outcome. Blood 123: 3790-3796, 2014.

9. Baliakas P, Hadzidimitriou A, Agathangelidis A, Rossi D, Sutton LA, Kminkova J, Scarfo L, Pospisilova S, Gaidano G, Stamatopoulos K, et al: Prognostic relevance of MYD88 mutations in CLL: The jury is still out. Blood 126: 1043-1044, 2015.

10. Improgo MR, Tesar B, Klitgaard JL, Magori-Cohen R, Yu L, Kasar S, Chaudhary D, Miao W, Fernandes SM, Hoang K, et al: MYD88 L265P mutations identify a prognostic gene expression signature and a pathway for targeted inhibition in CLL. Br J Haematol 184: 925-936, 2019.

11. Kim JA, Hwang B, Park SN, Huh S, Im K, Choi S, Chung HY, Huh J, Seo EJ, Lee JH, et al: Genomic profile of chronic lymphocytic leukemia in korea identified by targeted sequencing. PLoS One 11: e0167641, 2016

12. Cortese D, Sutton LA, Cahill N, Smedby KE, Geisler C, Gunnarsson R, Juliusson G, Mansouri L and Rosenquist R: On the way towards a 'CLL prognostic index': Focus on TP53, BIRC3, SF3B1, NOTCH1 and MYD88 in a population-based cohort. Leukemia 28: 710-713, 2014.

13. Lin SC, Lo YC and Wu H: Helical assembly in the MYD88-IRAK4-IRAK2 complex in TLR/IL-1R signalling. Nature 465: 885-890, 2010. 
14. Ngo VN, Young RM, Schmitz R, Jhavar S, Xiao W, Lim KH, Kohlhammer H, Xu W, Yang Y, Zhao H, et al: Oncogenically active MYD88 mutations in human lymphoma. Nature 470: 115-119, 2011.

15. Marino M, Monzani ML, Brigante G, Cioni K, Madeo B, Santi D, Maiorana A, Bettelli S, Moriondo V, Pignatti E, et al: High-resolution melting is a sensitive, cost-effective, time-saving technique for BRAF V600E Detection in thyroid FNAB washing liquid: A prospective cohort study. Eur Thyroid J 4: 73-81, 2015.

16. Chua KH, Lim SC, Ng CC, Lee PC, Lim YA, Lau TP and Chai HC: Development of high resolution melting analysis for the diagnosis of human malaria. Sci Rep 5: 15671, 2015.

17. Li J, Zhao GH, Lin R, Blair D, Sugiyama H and Zhu XQ: Rapid detection and identification of four major schistosoma species by high-resolution melt (HRM) analysis. Parasitol Res 114: 4225-4232, 2015.

18. Campregher PV and Hamerschlak N: Novel prognostic gene mutations identified in chronic lymphocytic leukemia and their impact on clinical practice. Clin Lymphoma Myeloma Leuk 14: 271-276, 2014.

19. Zenz T, Mertens D, Kuppers R, Döhner H and Stilgenbauer S: From pathogenesis to treatment of chronic lymphocytic leukaemia. Nat Rev Cancer 10: 37-50, 2010.

20. Soma LA, Craig FE and Swerdlow SH: The proliferation centre microenvironment and prognostic markers in chronic lymphocytic leukemia/small lymphocytic lymphoma. Hum Pathol 37: 152-159, 2006.

21. Oscier DG, Rose-Zerilli MJ, Winkelmann N, Gonzalez de Castro D, Gomez B, Forster J, Parker H, Parker A, Gardiner A, Collins A, et al: The clinical significance of NOTCH1 and SF3B1 mutations in the UK LRF CLL4 trail. Blood 121: 468-475, 2013

22. Mansouri L, Cahill N, Gunnarsson R, Smedby KE, Tjönnfjord E, Hjalgrim H, Juliusson G, Geisler C and Rosenquist R: NOTCH1 and SF3B1 mutations can be added to the hierarchical prognostic classification in chronic lymphocytic leukemia. Leukemia 27 521-514, 2013

23. Rossi D, Rasi S, Fabbri G, Spina V, Fangazio M, Forconi F, Marasca R, Laurenti L, Bruscaggin A, Cerri M, et al: Mutations of NOTCH1 are an independent predictor of survival in chronic lymphocytic leukemia. Blood 119: 521-529, 2012.

24. Montillo M, Hamblin T, Hallek M, Montserrat E and Morra E: Chronic lymphocytic leukemia: Novel prognostic factors and their relevance for risk-adapted therapeutic strategies. Haematologica 90: 391-399, 2005.

25. Kawasaki T and Kawai T: Toll-like receptor signalling pathways. Front Immunol 5: 461, 2014
26. Gay NJ and Keith FJ: Drosophila toll and IL-1 receptor. Nature 351: 355-356, 1991.

27. Schmidt U, Hulkkonen J and Naue J: Detection of a G>C single nucleotide polymorphism within a repetitive DNA sequence by high-resolution DNA melting. Int J Legal Med 130: 1181-1184, 2016.

28. Poon KS, Liu TC, Tan ML and Koay ES: One-step molecular detection of the MYD88 L265P mutation by unlabeled probe genotyping analysis. Mol Cell Probes 29: 74-77, 2015.

29. Rose-zerilli MJ, Gonzalez D, Gomez B, Parker H, Gardiner A, Parker A, Collins A, Catovsky D, Oscier DG and Strefford JC: The clinical significant of NOTCH1 and MYD88 mutations in patients enrolled onto the UK CLL4 treatment trial and in an early stage A cll cohort. Clin Lymph Myelom Leuk 11 (Suppl 2): S229, 2011.

30. Xu JJ, Yao FR, Jiang M, Zhang YT and Guo F: High-resolution melting analysis for rapid and sensitive NOTCH1 screening in chronic lymphocytic leukemia. Int J Mol Med 39: 415-422, 2017.

31. Sady H, Al-mekhlafi HM, Ngui R, Atroosh WM, Al-Delaimy AK, Nasr NA, Dawaki S, Abdulsalam AM, Ithoi I, Lim YA, et al: Detection of schistosomamansoni and schistosomahaematobium by real-time PCR with high resolution melting analysis. Int J Mol Sci 16: 16085-16103, 2015.

32. Hauss $\mathrm{O}$ and Müller $\mathrm{O}$ : The protein truncation test in mutation detection and molecular diagnosis. Methods Mol Biol 375: 151-164, 2007.

33. Hayashi K: PCR-SSCP: A method for detection of mutations. Genet Anal Tech Appl 9: 73-79, 1992.

34. de Juan Jiménez I, Cardeñosa EE, Suela SP, González EB, Trejo DS, Lluch OF and Gilabert PB: Advantage of high-resolution melting curve analysis over conformation-sensitive gel electrophoresis for mutational screening of BRCA1 and BRCA2 genes. Clin Chim Acta 412: 578-582, 2011.

35. Chang YS, Lin CY, Yang SF, Ho CM and Chang JG: High-resolution melting analysis for gene scanning of adenomatous polyposis coli (APC) gene with oral squamous cell carcinoma samples. Appl Immunohistochem Mol Morphol 24: 97-104, 2016

36. Hondow HL, Fox SB, Mitchell G, Scott RJ, Beshay V, Wong SQ, kConFab Investigators and Dobrovic A: A high-throughput protocol for mutation scanning of the BRCA1 and BRCA2 genes. BMC Cancer 11: 265, 2011.

This work is licensed under a Creative Commons Attribution-NonCommercial-NoDerivatives 4.0 International (CC BY-NC-ND 4.0) License. 